\title{
Effects of Stirrups on Bond Behavior Between Concrete and Corroded Steel Bars
}

\author{
Hongwei Lin, Yuxi Zhao, and Ming Sun \\ Institute of Structural Engineering, Zhejiang University
}

\begin{abstract}
Steel corrosion leads to the deterioration of bond between concrete and steel bars. The serviceability and ultimate strength of concrete elements within RC structures are hence affected. Many researchers have studied the bond behavior of corroded steel bars. However, very few studies have investigated the effects of confinements on the degradation of bond strength. The present paper proposed a new kind of beam specimen based on which the effects of stirrups on degradation of bond were investigated. The test results proved that stirrups can effectively increase the bond strength between concrete and corroded steel bars.
\end{abstract}

\section{INTRODUCTION}

Steel corrosion is one of the serious durability problems that more and more RC structures face. Steel corrosion causes damage to structures in three aspects: loss of cross-sectional area of steel bar and concrete, reduction of the mechanical properties of steel bar, and weakening of bond between concrete and steel bars. The deterioration of bond can affect the serviceability and ultimate strength of concrete elements significantly. After corrosion, the volume of parent steel will increase. The ratio between the volume of rust products and virgin steel can be 2:4 (Pantazopoulou \& Papoulia, 2001). The expansive corrosion products will induce hoop tensile stress in the surrounding concrete. In the initial stage of corrosion, the bond strength will increase because of the increased roughness of steel bar. After cracking of concrete cover, the bond strength will decrease because of the reduction of confinement. Many researchers have investigated the degradation of bond strength by experiments and proposed empirical formulas to describe the relationship between bond strength and corrosion level (Auyeung, Balaguru, et al., 2000; Cabrera, 1996; Chung, Jay Kim, et al., 2008; Lee, Noguchi, et al., 2002). However, widely accepted degradation model is still beyond reach because of the difference in experimental details. In addition, most of the experiments were performed on specimens without stirrups. Very few studies have investigated the degradation of bond in concrete with confinements (stirrups, FRPs, steel fiber reinforced concrete). Previous studies showed that confinements can control the development of cracking and put off the degradation of bond strength effectively (Fang, Lundgren, et al., 2004; Zhao, Lin, et al., 2013). Thus, further study is needed to investigate the effects of confinements on bond degradation.
The present paper investigated the effects of stirrups on the degradation of bond strength based on beam specimens. The principal parameters investigated were corrosion level and stirrup index. Finally, an empirical formula was established to describe the degradation of bond strength.

\section{EXPERIMENTAL PROGRAM}

\subsection{Specimens and materials}

All the beam specimens had a cross-section of $150 \mathrm{~mm} \times 250 \mathrm{~mm}$ with concrete cover $40 \mathrm{~mm}$. The bond length at beam end was $150 \mathrm{~mm}$ to ensure that bond slip failure would dominate. PVC sleeve was used to debond the remaining length of steel bar. Slots with a cross-section of $150 \mathrm{~mm} \times 100 \mathrm{~mm}$ were made at each end of the beam to measure the pullout force and slip at the load end. Three different stirrup spacings of 200 (series I), 100 (series II), and $70 \mathrm{~mm}$ (series III) were arranged. Details about the beam specimen are shown in Figure 1.

Commercial concrete was used in this experiment and the compressive strength of the concrete is $30 \mathrm{MPa}$. The diameter of the tensile steel bar was $20 \mathrm{~mm}$ and the yield strength is $540 \mathrm{MPa}$. Two 12-mm deformed steel bars with yield strength of $235 \mathrm{MPa}$ were arranged at the top. The diameter of the stirrups was $8 \mathrm{~mm}$ and the yield strength was $235 \mathrm{MPa}$.

\subsection{Acceleration of steel corrosion}

Steel corrosion was induced by impressing direct currents on the specimens. The designed corrosion levels in the present paper were $0,3,6,9,12$, and $15 \%$. To approximate actual corrosion modality, the "wetting-drying cycle" method was adopted (Zhao et al., 2013). The corrosion percentage was determined by measuring the weight of the steel bars 


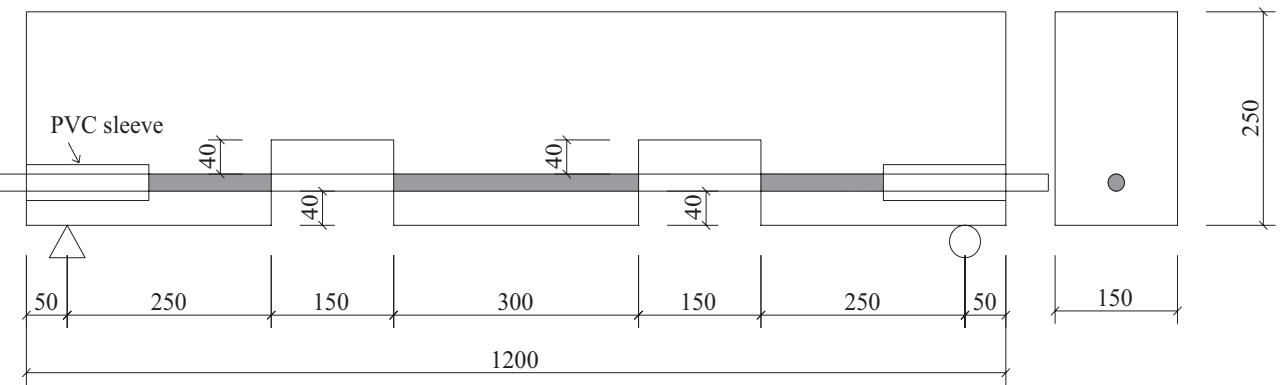

Figure 1. Beam specimen dimensions.

after removing the corrosion products. The achieved corrosion levels were shown in Table 1. The characters "L" and "R" represent the left end and right end of the beam specimen, respectively. It should be noted that the stirrups in the experiment were corroded.

Table 1. Specimen details and corrosion levels.

\begin{tabular}{|c|c|c|c|c|}
\hline $\begin{array}{l}\text { Specimen } \\
\text { Number }\end{array}$ & $\begin{array}{l}\text { Stirrup } \\
\text { Spacing }\end{array}$ & $\begin{array}{c}\text { Designed } \\
\text { Corrosion } \\
(\%)\end{array}$ & $\begin{array}{c}\text { Measured } \\
\text { Corrosion } \\
(\mathrm{L}, \%)\end{array}$ & $\begin{array}{c}\text { Measured } \\
\text { Corrosion } \\
(\mathrm{R}, \%)\end{array}$ \\
\hline $\mathrm{BI}-0$ & \multirow{6}{*}{ Ф6@200 } & 0 & 0 & 0 \\
\hline $\mathrm{BI}-3$ & & 3 & 4.516 & 8.002 \\
\hline BI-6 & & 6 & 7.642 & 4.296 \\
\hline BI-9 & & 9 & 13.603 & 12.314 \\
\hline $\mathrm{BI}-12$ & & 12 & 17.237 & 11.061 \\
\hline $\mathrm{BI}-15$ & & 15 & 16.108 & 20.860 \\
\hline BII-0 & \multirow{6}{*}{ Ф6@100 } & 0 & 0 & 0 \\
\hline BII-3 & & 3 & 2.037 & 2.753 \\
\hline BII-6 & & 6 & 4.523 & 2.713 \\
\hline BII-9 & & 9 & 6.687 & 8.189 \\
\hline BII-12 & & 12 & 16.772 & 13.670 \\
\hline BII-15 & & 15 & 16.097 & 15.466 \\
\hline BII-0 & \multirow{6}{*}{ Ф6@70 } & 0 & 0 & 0 \\
\hline BII-3 & & 3 & 1.012 & 2.239 \\
\hline BII-6 & & 6 & 3.859 & 4.059 \\
\hline BII-9 & & 9 & 9.430 & 7.309 \\
\hline BII-12 & & 12 & 9.143 & 9.943 \\
\hline BII-15 & & 15 & 16.327 & 14.352 \\
\hline
\end{tabular}

\subsection{Loading procedure}

The beam specimens were tested as simply supported beams with concentrated loads using an automatic hydraulic testing machine as seen in Figure $2 a$. All the specimens were loaded in displacement control at a rate of $0.5 \mathrm{~mm} / \mathrm{min}$. Within the exposed $150-\mathrm{mm}$ steel bar, the strain gauges were fixed on the bottom and side of the bar to measure the tensile strain. Both the load and free end slips of the bars were measured using four dial indicators.

With the increase of the load, anchor failure occurred at one end of the beam firstly. When the free end slip reached required value, the steel bar at the damaged end would be anchored by a special anchorage device, and the load would increase again. The loading procedure would not be stopped until anchor failure occurred at the other end of the beam and corresponding free end slip reached required value. The anchor of the damaged beam end is shown in Figure 2b.

\section{RESULTS AND DISCUSSION}

\subsection{Effects of stirrups on the degradation of bond strength}

Average bond strength, $\mu$, was calculated based on the following equation:

$$
\mu=\frac{P}{\pi d l}
$$

where $P$ is the maximum pullout load, $d$ is the bar diameter, and $l$ is the bond length of steel bar.

$\mu_{0}$ is defined as the bond strength of specimens without corrosion, $\mu_{\mathrm{c}}$ is defined as the bond strength of

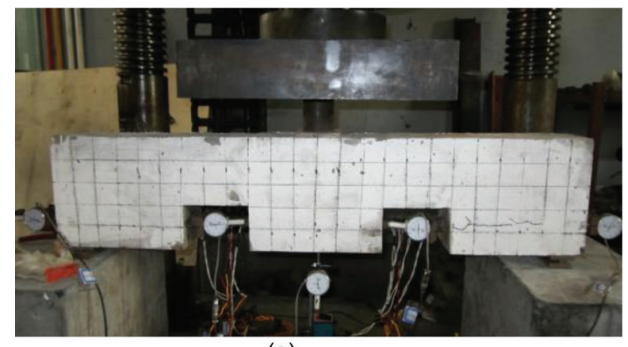

(a)

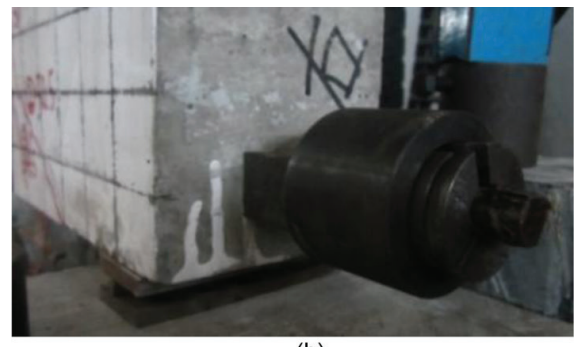

(b)

Figure 2. Loading method: (a) concentrated loading and (b) anchor of the damaged beam end. 


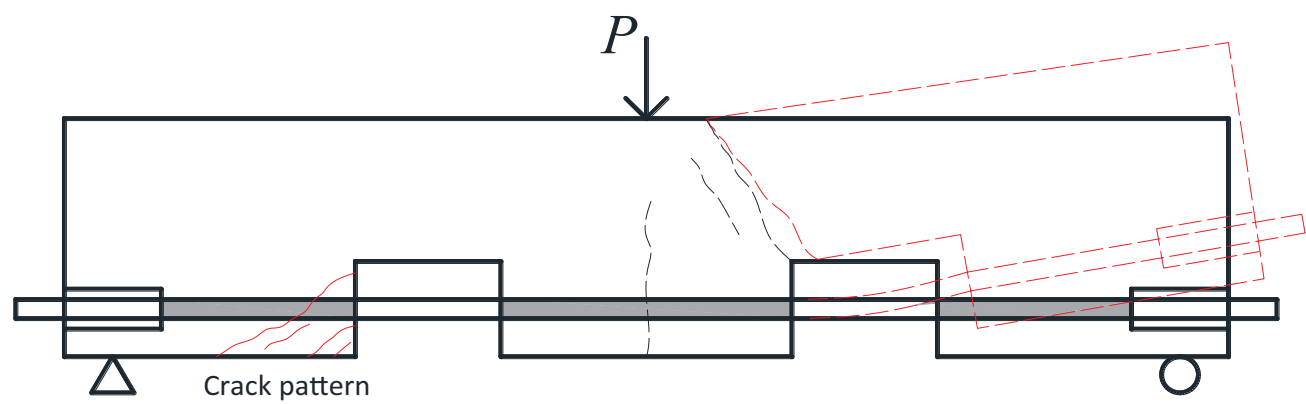

Figure 3. Sketch of the cracking of the beam.
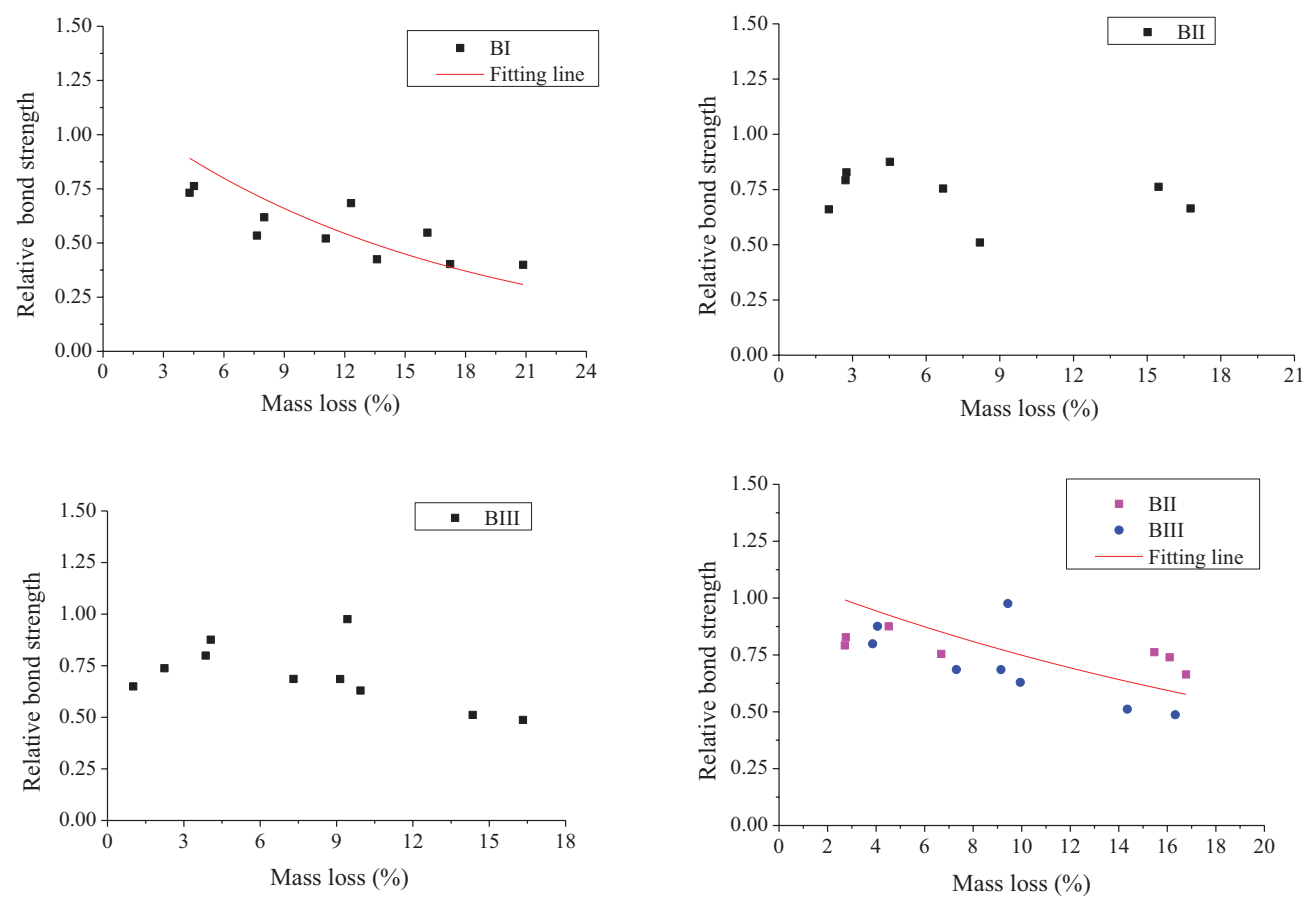

Figure 4. Relationship between relative bond strength and corrosion level.

corroded specimens, and $\mu_{\mathrm{r}}$ is defined as relative bond strength, and it can be expressed as follows:

$$
\mu_{\mathrm{r}}=\frac{\mu_{\mathrm{c}}}{\mu_{0}}
$$

Figure 4 shows the relationship between bond strength and steel corrosion. For series $\mathrm{BI}$, the bond strength decreased rapidly as the corrosion level increased. However, the degradation for series BII and BIII was not as serious as series $\mathrm{BI}$. The reason is that stirrups can control the development of cracking and hence increase the confinement of the steel bar. As mentioned above, the bond strength increases initially and decreases rapidly afterward (AI-Sulaimani, Kaleemullah, et al., 1990; Chung et al., 2008). The critical corrosion level after which bond strength begins to decrease by Al-Sulaimani was 0.5 and $1 \%$ for pullout specimens and beam specimens, respectively. Chung found that the critical corrosion level was $2 \%$. Figure 5 by Zhao et al. (2013) summarized the test results from previous researchers. It can be concluded from Figure 5 that the critical corrosion level is about $2.5 \%$.

Cabrera (1996) and Stanish, Hooton, et al. (1999) established linear relationship between bond strength and steel corrosion by regression analysis, while Auyeung et al. (2000), Lee et al. (2002), Bhargava, Ghosh, et al. (2006), and Chung et al. (2008) used exponent model to describe the degradation of bond strength. In the present paper, the following degradation model is established:

$$
\begin{gathered}
\mu_{\mathrm{r}}=1 \quad \eta \leq 2.5 \% \\
\mu_{\mathrm{r}}=\mathrm{e}^{-\mathrm{a}(\eta-0.025)}, \eta>2.5 \%
\end{gathered}
$$




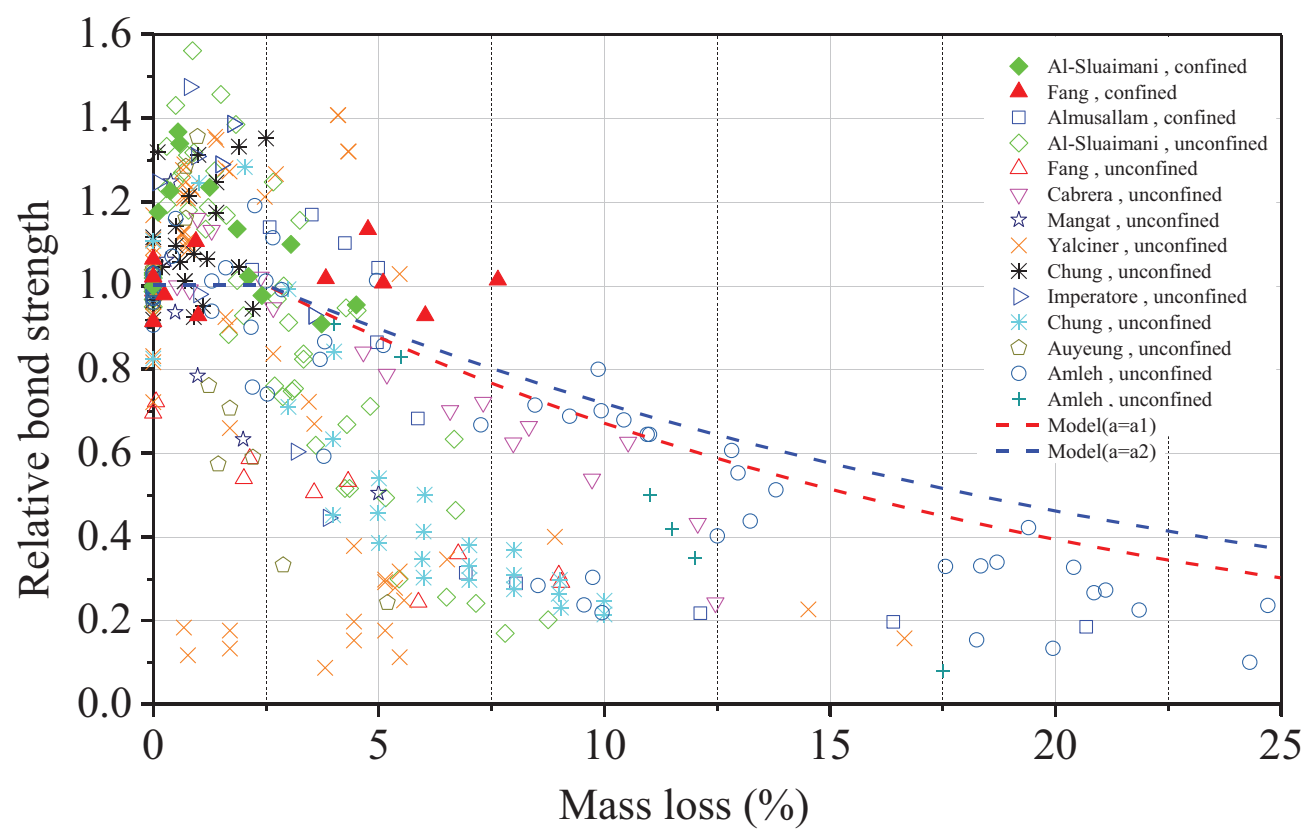

Figure 5. Test results from previous researches.

where $a$ is the degradation coefficient that is influenced by stirrups and concrete cover and $\eta$ is corrosion level. As the test results from series BII and BIII are somehow scattered, the data from series BII and BIII are put together for regression analysis. The degradation coefficient for series $\mathrm{BI}, \mathrm{BII}$, and BIII by regression analysis is shown in Table 2.

Table 2. Degradation coefficient by regression analysis.

\begin{tabular}{lcccc}
\hline Specimen Number & $\boldsymbol{\xi}_{\text {st }}$ & $\boldsymbol{a}$ & $\boldsymbol{R}^{2}$ & $\boldsymbol{\sigma}$ \\
\hline $\mathrm{BI}$ & 0.014 & 6.405 & 0.015 & 0.839 \\
$\mathrm{BII}$ & 0.028 & 3.855 & -0.097 & 0.664 \\
$\mathrm{BIII}$ & 0.040 & & & \\
\hline
\end{tabular}

To quantify the effects of stirrups, stirrup index $\xi_{\text {st }}$ is introduced, and $\xi_{\text {st }}$ is defined as

$$
\xi_{\mathrm{st}}=\frac{n_{\mathrm{st}} A_{\mathrm{st}}}{n_{\mathrm{p}} d_{\mathrm{p}} \Delta}
$$

where $n_{\mathrm{st}}$ is the number of legs of stirrups, $A_{\mathrm{st}}$ is the crosssectional area of one leg of stirrups, $n_{p}$ is the number of anchored bars, $d_{\mathrm{p}}$ is the diameter of the anchored bar, and $\Delta$ is the longitudinal spacing of stirrups.

Figure 6 shows the relationship between degradation coefficient and stirup index. If $\xi_{\mathrm{st}}(3.855)=0.028$, a can be expressed as

$$
a_{1}=-180.389 \xi_{\text {st }}+8.955
$$

If $\xi_{\mathrm{st}}(3.855)=0.040, a$ can be expressed as

$$
a_{2}=-97.133 \xi_{\text {st }}+7.778
$$

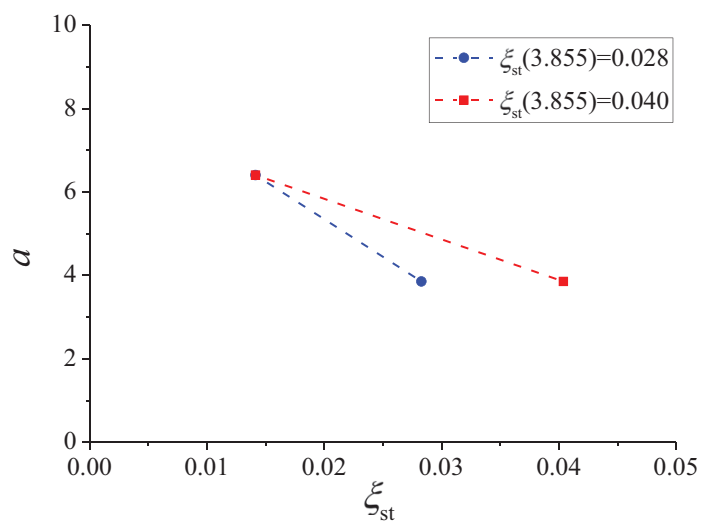

Figure 6. Relationship between degradation coefficient and corrosion level.

Degradation coefficient for specimens with stirrups should varies between $a_{1}$ and $a_{2}$. The shadow in Figure 7 shows the range of $a$.

As $8 \mathrm{~mm}$ stirrup with a spacing of $200 \mathrm{~mm}$ is usually arranged in the engineering design, the stirrup index and degradation coefficient are calculated by Equations (5)-(7). $\xi_{\text {st }}$ is $0.0251, a_{1}$ and $a_{2}$ are 5.340 and 4.427 , respectively. The obtained degradation model is compared with test results in Figure 5. It can be seen that test results from specimens without stirrups are almost all smaller than value given by the model. This proves that test results from previous researches underestimate the bond strength in corroded RC elements. It should be pointed out that some data from Fang et al. (2004) are above the curve by the model. This is because the stirrups index from Fang is 0.707 , which is larger than that of the model. In addition, the stirrups from Fang are hardly corroded. 


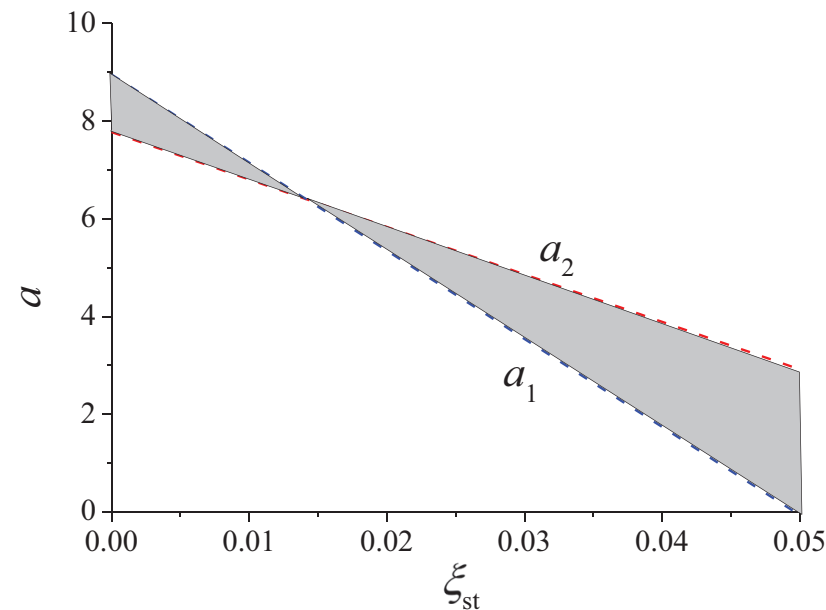

Figure 7. Fluctuation range of degradation coefficient.

\section{CONCLUSION}

The present article introduced a new beam specimen based on which the degradation of bond strength was investigated. Compared with commonly used concentric pullout specimen, the new beam specimen can reflect the actual bond behavior realistically. Three stirrup spacings were arranged to determine the effects of stirrups on bond degradation. The test results proved that degradation coefficient decreases with the increase of stirrup index. By comparing with test results from specimens without stirrups, it was found that confining concrete with stirrups was an effective way to improve bond strength of corroded specimens.

\section{ACKNOWLEDGMENTS}

Financial support from the Zhejiang Provincial Natural Science Foundation via Grant LR12E08001 and Ministry of Education of China with Grant NCET-120493 is gratefully acknowledged.

\section{REFERENCES}

Auyeung, Y., Balaguru, P., \& Chung, L. (2000). Bond behavior of corroded reinforcement bars. $\mathrm{ACl}$ Materials Journal, 97(2), 214-220.

Cabrera, J. G. (1996). Deterioration of concrete due to reinforcement steel corrosion. Cement and Concrete Composites, 18(1), 47-59.

Chung, L., Jay Kim, J.-H., \& Yi, S.-T. (2008). Bond strength prediction for reinforced concrete members with highly corroded reinforcing bars. Cement and Concrete Composites, 30(7), 603-611.

Fang, C., Lundgren, K., Chen, L., \& Zhu, C. (2004). Corrosion influence on bond in reinforced concrete. Cement and Concrete Research, 34(11), 2159-2167.

Lee, H.-S., Noguchi, T., \& Tomosawa, F. (2002). Evaluation of the bond properties between concrete and reinforcement as a function of the degree of reinforcement corrosion. Cement and Concrete Research, 328, 1313-1318.

Pantazopoulou, S. J., \& Papoulia, K. D. (2001). Modeling cover-cracking due to reinforcement corrosion in RC structures. Journal of Engineering Mechanics, 127(4), 342-351.

Zhao, Y., Lin, H., Wu, K., \& Jin, W. (2013). Bond behaviour of normal/recycled concrete and corroded steel bars. Construction and Building Materials, 48, 348-359. 